\title{
Contribuições de Paulo Freire na formação de professores para a Educação de Jovens e Adultos: uma análise da produção científica sob a ótica do Methodi Ordinatio
}

\author{
Paulo Freire's contributions in teacher training for Youth and Adult Education: an \\ analysis of scientific production from the perspective of Methodi Ordinatio
}

\author{
Juliane Retko Urban ${ }^{1}$ \\ Antonio Carlos Frasson ${ }^{2}$
}

\begin{abstract}
Resumo
Este artigo, na forma de pesquisa de revisão bibliográfica sistemática, objetiva identificar a produção científica referente à contribuição de Paulo Freire para a formação de professores, na modalidade de Educação de Jovens e Adultos, EJA. A pesquisa foi realizada com a metodologia denominada Methodi Ordinatio. A questão norteadora foi: Quais as contribuições de Paulo Freire para a formação de professores da modalidade de educação de jovens e adultos? Do ponto de vista da problemática, a pesquisa se caracteriza como de cunho qualitativo, pois visa conhecer o que a literatura apresenta sobre as questões centrais do tema. Como resultado do levantamento, obteve-se, inicialmente, 182 (cento e oitenta e dois) artigos. Após o processo de filtragem e eliminação de duplicatas e títulos não pertencentes à área de pesquisa, restaram 105 (cento e cinco) artigos; dos quais foram lidos o título e o resumo, e verificou-se que 10 (dez) artigos se referem aos temas, em conjunto: formação de professores, educação de jovens e adultos e Paulo Freire. Constatou-se as contribuições de Paulo Freire para a EJA e que existem possibilidades de pesquisa direcionando essas contribuições para a formação de professores nessa modalidade de ensino.
\end{abstract}

Palavras-chave: Educação de Jovens e Adultos. Formação de Professores. Methodi Ordinatio. Paulo Freire.

\begin{abstract}
This article, in the form of a systematic bibliographic review research, aims to identify the scientific production on the theme of Paulo Freire's contribution to teacher education, in

\footnotetext{
'Doutoranda no Programa de Pós-Graduação em Ensino de Ciência e Tecnologia (UTFPR). Bolsista CAPES. Mestra em Ensino de Ciência e Tecnologia (UTFPR). Graduada em Pedagogia (UEPG). Tecnóloga em Alimentos (CEFET-PG). Membro do Grupo de Pesquisa Educação à Distância: Formação Docente para o Ensino de Ciência e Tecnologia. E-mail: juretko.urban@gmail.com

${ }^{2}$ Doutor em Educação pela Universidade Metodista de Piracicaba. Professor Adjunto da Universidade Tecnológica Federal do Paraná - UTFPR Câmpus Ponta Grossa. Está vinculado ao Programa de PósGraduação em Ensino de Ciência e Tecnologia (PPGECT) no Câmpus Ponta Grossa. É líder do grupo de pesquisa Educação a Distância: Formação Docente para o Ensino de Ciência e Tecnologia. E-mail: ancafra@gmail.com
} 


\section{-Revista de Iniciação à Docência, v.6 , n. 2, 2021- \\ Publicação: dezembro, 2021 - ISSN 2525-4332}

the form of Youth and Adult Education. The research was carried out with the methodology called Methodi Ordinatio. The guiding question was: What are Paulo Freire's contributions to the training of teachers in the youth and adult education modality? From the point of view of the issue, it is characterized by a qualitative nature, as it seeks to know what the literature puts on the central issues of the theme. As a result of the survey, initially 182 articles were obtained, after the process of filtering and eliminating duplicates and titles outside the research area, 105 articles remained. Of these 105, the title and abstract were read and 10 articles referred to teacher training, youth and adult education and Paulo Freire. It was observed in this study that there are research possibilities when directed to the contributions of Paulo Freire with the training of teachers for the education of young people and adults.

Keywords: Youth and Adult Education. Teacher training. Methodi Ordinatio. Paulo Freire.

\section{Introdução}

A pesquisa apresenta autores que exploraram as contribuições de Paulo Freire na EJA e a formação de professores, nesse segmento de ensino, sendo realizado o levantamento e análise por meio da revisão bibliográfica sistemática.

A revisão sistemática de determinado assunto se faz necessária para o conhecimento da comunidade científica sobre o tema e para verificar as pesquisas e discussões acadêmicas sobre tal. Para essa pesquisa, em específico, a revisão foi realizada como estudo preliminar de um projeto de pós-graduação.

Com o aumento de publicações científicas, nos últimos anos, a seleção de material para o apoio bibliográfico nas pesquisas se tornou complexa. Por isso, a escolha de materiais relevantes e significativos, que abrangem o tema delimitado, exigiu critérios adequados para a seleção de artigos científicos.

Para isso, foi utilizada a metodologia denominada Methodi Ordinatio, que utiliza a ordenação de relevância, de acordo com o fator de impacto, ano de publicação e número de citações de cada trabalho encontrado, para a busca do material que compõe a revisão bibliográfica. As bases consultadas foram: Scielo, Scopus e Web of Science. As palavraschave utilizadas foram: "educação de jovens e adultos", "formação de professores" e "Paulo Freire". Palavras em inglês foram necessárias na busca, utilizando-se, contudo, algumas traduções similares aos termos originais, como, por exemplo: para "formação de professores", utilizamos teacher training, formation of teachers, teacher training programs e teacher education programmes.

Por se tratar de uma revisão sistemática, o Methodi Ordinatio foi utilizado para apresentar os artigos mais relevantes indexados nas bases de dados já citadas, para, com isso, informar sobre os estudos do educador Paulo Freire na atualidade. O propósito foi verificar se existem lacunas entre as pesquisas referentes ao educador Paulo Freire, a formação de professores e a EJA, temas discutidos e investigados há anos. 


\section{-Revista de Iniciação à Docência, v.6 , n. 2, 2021- \\ Publicação: dezembro, 2021 - ISSN 2525-4332}

A questão norteadora da pesquisa foi: Quais as contribuições de Paulo Freire para a formação de professores da modalidade da EJA?

A partir desta questão, portanto, a pesquisa buscou identificar a produção científica sobre a contribuição de Paulo Freire para a formação de professores, na modalidade da EJA, utilizando-se a Revisão Bibliográfica Sistemática, RBS.

A EJA é um tema que envolve inúmeras discussões, haja vista que os autores que pesquisam nesta área sempre estão a se posicionar e discutir sobre novos conhecimentos, principalmente neste momento de pandemia.

\section{A formação de professores no contexto da EJA: contribuições de Paulo Freire}

A educação é um fator de transformação social e de crescimento, pois possibilita o conhecimento, a quem tem acesso a ela, e a construção do pensamento autônomo e crítico. A partir desse ponto de vista, e, segundo a Constituição (BRASIL, 1988), é direito de todos o acesso à educação e dever do Estado garanti-la a todos os brasileiros.

Ao discorrer sobre educação, Pinto (1991) debate e apresenta como permanente, pois a sociedade está sempre equipando seus membros com conhecimentos e atitudes que permitem a sobrevivência do grupo humano. Contudo, o interesse da sociedade, para fins coletivos, de aproveitar ao máximo a força de trabalho de cada um de seus membros, leva, muitas vezes, os alunos a interromperem seus estudos e o acesso à educação durante a infância ou a juventude, tendo sua formação educacional comprometida.

Além do trabalho, o acesso à educação pode ser negado ao indivíduo pelas mais diferentes razões, como as condições econômicas desfavoráveis, falta de vagas nas escolas ou a precariedade do ensino. Quando se tem a oportunidade de retornar à escola, os alunos passam a fazer parte da EJA, modalidade que está descrita na Lei de Diretrizes e Bases da Educação Nacional, LDBEN, na seção V, no artigo 37, conforme segue:

\footnotetext{
A educação de jovens e adultos será destinada àqueles que não tiveram acesso ou continuidade de estudos nos ensinos fundamental e médio na idade própria e constituirá instrumento para a educação e a aprendizagem ao longo da vida. (BRASIL, 1996)
}

Anteriormente à LDBEN n 9394/96, já havia, no Brasil, movimentos que atuavam na educação de adultos. O propósito, neste estudo, é analisar as contribuições de Paulo Freire nessa modalidade de ensino, haja vista que esse educador brasileiro - conhecido mundialmente - foi o precursor da alfabetização de pessoas adultas no Brasil. Em Angicos, em janeiro de 1963, foram alfabetizados os trabalhadores da região em 40 (quarenta) horas de estudo. Pelandré (1998, p. 40) fala sobre as aulas ministradas:

As aulas eram chamadas de "círculos de cultura", espaço de desenvolvimento dos debates sobre a realidade existencial dos alfabetizandos, momento em que 


\title{
-Revista de Iniciação à Docência, v.6 , n. 2, 2021- Publicação: dezembro, 2021 - ISSN 2525-4332
}

os monitores, através dos "temas geradores", problematizavam as situações, estimulando a participação e o posicionamento crítico.

Nesse contexto, Borges (2020, p. 3) aborda o legado de Paulo Freire acerca do uso das palavras geradoras como procedimento para a alfabetização:

No início dos anos 60, o pensamento pedagógico de Paulo Freire inspirou os principais programas de alfabetização e de educação popular no país. Freire elaborou uma proposta de alfabetização de adultos conscientizadora, cujo princípio básico era "a leitura do mundo" que precedia "a leitura da palavra". Naquela época, Freire já intervinha nas dificuldades de aprendizagem, utilizando como procedimento as Palavras Geradoras.

As palavras geradoras são aquelas utilizadas no cotidiano do educando e é a partir delas que se inicia o processo de alfabetização, pois o vínculo com o cotidiano facilita o entendimento e desperta o interesse por aprender.

Compreende-se que, ao longo da história, a EJA foi marcada por políticas públicas de descontinuidade e de desvalorização do jovem e do adulto, deixando-os à margem de um sistema educacional que primava pelas condições econômicas de uma minoria (CASSOL; PEREIRA; AMORIM, 2021).

Assim, Pelandré (1998, p. 37), em sua tese, relata que Paulo Freire:

\begin{abstract}
Costumava dizer que não tinha método: o que havia ocorrido tinha por motivação a curiosidade, de um lado, e o seu compromisso político, do outro, em face aos renegados, aos proibidos de ler a palavra, relendo o mundo, tentou e continuou a buscar uma compreensão crítica ou dialética da prática educativa, dentro da qual há, necessariamente, uma prática alfabetizadora que implica uma metodologia, um certo método, que prefere chamar de "método de conhecer" e não de método de ensinar.
\end{abstract}

Diante do desenvolvimento do "método de conhecer", Freire trabalhou com temas geradores. Pelandré (1998, p. 40) destaca o momento em que Freire e Maciel abordam sobre as pessoas analfabetas: "o que o analfabeto não tinha, segundo o entender de Paulo Freire e Jarbas Maciel, era a passagem do sistema de sinalização verbal para o subsistema gráfico", e os temas geradores advém de palavras do cotidiano do educando, usuais em sua vida pessoal e/ou profissional, os quais facilitam, no processo, a aprendizagem do subsistema gráfico:

Estas palavras são chamadas geradoras porque, através da combinação de
seus elementos básicos, propiciam a formação de outras. Como palavras do
universo vocabular do alfabetizando, são significações constituídas ou
reconstituídas em comportamentos seus, que configuram situações
existenciais ou, dentro delas, se configuram. Tais significações são
plasticamente codificadas em quadros, slides, filminas etc., representativos
das respectivas situações, que, da experiência vivida do alfabetizando,
passam para o mundo dos objetos. O alfabetizando ganha distância para
ver sua experiência: "admirar". Nesse instante, começa a descodificar
(FREIRE, 2020b, p. 14).

Ao trabalhar com as palavras geradoras, Freire posiciona o aluno no centro do processo de aprendizagem. Dessa forma, a proposta de utilização de temas geradores tem o intuito de facilitar o aprendizado dos alunos, por serem temas relacionados aos 


\section{-Revista de Iniciação à Docência, v.6 , n. 2, 2021- \\ Publicação: dezembro, 2021 - ISSN 2525-4332}

aspectos de suas vidas, ou seja, relacionados diretamente com o seu cotidiano. A partir deles, acontece, portanto, o desenvolvimento das aulas, sem a necessidade das abordagens teóricas e conceituais dos livros didáticos. Os conteúdos se tornam abrangentes e complexos, pois envolvem diversas dimensões da realidade e proporcionam uma visão da totalidade da sociedade (PAULA; BARBOSA, 2021).

Freire (2020a, p. 31) também aborda sobre o ensinar, que exige respeito aos saberes dos educandos:

Por que não discutir com os alunos a realidade concreta a que se deva
associar a disciplina cujo conteúdo se ensina, a realidade agressiva em que
a violência é a constante e a convivência das pessoas é muito maior com a
morte do que com a vida? Por que não estabelecer uma "intimidade" entre
os saberes curriculares fundamentais aos alunos e a experiência social que
eles têm como indivíduos?

Ressalta-se a importância, no contexto da EJA, de que os professores atuem próximos da realidade, do cotidiano, dos alunos, para que, assim, possam aproximá-los da sua prática, despertando o interesse pelo estudo, visando evitar a evasão.

Freire (2020a) relata que a leitura de mundo precede à leitura da palavra, ou seja, a pessoa, desde criança, aprende primeiro a ler o mundo, por meio da leitura de objetos, sinais, relações com outras pessoas e o que mais estiver ao seu redor. Assim, quando adentra à escola, traz consigo a sua cultura, a qual não é, nem melhor, nem pior do que a do professor. A partir desse entendimento, o ensinar para as pessoas jovens e adultas têm outro sentido e sua compreensão é facilitada quando os conteúdos a serem ministrados partem do cotidiano do educando.

Outro ponto a ser considerado na pedagogia freireana é o potencial de promover uma aprendizagem que tenha significado e sentido (PAULA; BARBOSA, 2021). Quando se promove a aprendizagem com significado e sentido, adentra-se numa nova perspectiva de ensino, a educação problematizadora. Para Freire (1975, p. 94):

A problematização é dialética, que seria impossível para alguém estabelecê-
la, sem se comprometer com o processo. Ninguém problematiza algo para
alguém e permanece, ao mesmo tempo, um mero espectador. Mesmo
quando, metodologicamente, prefere calar-se ao apresentar o fato-
problema, assim que os alunos o apreenderem, analisarem,
compreenderem, também estarão sendo problematizados.

A educação problematizadora, para o público da EJA, é uma opção para o propósito da educação nesta modalidade, propondo a aproximação curricular por meio dos conhecimentos do cotidiano dos alunos; pois o educando da EJA traz consigo ricas experiências e conhecimentos diversos, os quais podem ser usados para gerar as problematizações em sala de aula. Os professores que atuam na EJA necessitam de formação e a continuada se torna uma excelente alternativa. Segundo Cassol, Pereira, Amorim (2021, p. 13):

Observamos que há um descompasso diante dos processos formativos atuais e as novas exigências freireanas de atuação do educador da EJA [...] E o professor é um agente destas novas concepções formativas, que 


\section{-Revista de Iniciação à Docência, v.6 , n. 2, 2021- \\ Publicação: dezembro, 2021 - ISSN 2525-4332}

exigem um repensar, um ponto de partida para concretizar a formação do docente, de modo paralelo à realidade social moderna, vigorando a prática emancipatória educacional da EJA.

A formação continuada, no cenário pandêmico atual, gera uma série de expectativas expressadas pelos modelos da sociedade global. A EJA não se resume somente a suprir necessidades de ensino, pois é direito de todos os indivíduos que trazem trajetórias escolares e estilos de vidas singulares (FRANCO; ANDRADE, 2021, p. 4).

A EJA, para os seus educandos, tem como um dos seus objetivos principais o preparo do aluno para uma educação de qualidade e a sua inserção no mercado de trabalho. Logo, a educação passa a ser considerada como ponto central do desenvolvimento dos indivíduos, e os professores, em uma relação de afetividade com os educandos, são integrantes desse progresso.

\section{Procedimentos Metodológicos}

Para ampliar e conhecer as discussões no campo da pesquisa da formação de professores para a EJA, relacionada às contribuições de Paulo Freire, optou-se pela realização de uma Revisão Bibliográfica Sistemática, RBS; a qual, segundo Galvão (2019, p. 2) é "uma modalidade de pesquisa que segue protocolos específicos e busca dar alguma logicidade a um grande corpus documental. Revisar a literatura é atividade essencial no desenvolvimento de trabalhos acadêmicos e científicos".

A escolha das bases de dados foi definida por sua amplitude e/ou alcance. A base Scielo permite o acesso eletrônico aos artigos completos de revistas da Argentina, Brasil, Chile, Colômbia, Cuba, Costa Rica, Venezuela, Bolívia, Peru, Uruguai, Espanha, Portugal e África do Sul. Atende as necessidades de comunicação científica na América Latina e no Caribe. A Scopus, por sua vez, foi utilizada por ser o maior banco de dados de resumos e citações com revisão por pares.

Na Tabela 1 estão descritos os resultados obtidos na busca, em cada base de dados pesquisada, e as palavras-chave utilizadas. A busca dos artigos, a partir das combinações, ocorreu com base na seleção de dados, os quais demonstraram maior proximidade com a área de pesquisa e foram: Scielo, Scopus e Web of Science. Foi realizada busca na Science Direct, mas, por apresentar apenas 3 (três) artigos e por estarem indexados em outras bases, optou-se por retirá-la da apresentação da base, na tabela. 
-Revista de Iniciação à Docência, v.6 , n. 2, 2021-

Publicação: dezembro, 2021 - ISSN 2525-4332

Tabela 1: Quantidade de artigos

\begin{tabular}{|c|c|c|c|c|}
\hline Palavras-chave & Scopus & $\begin{array}{l}\text { Web os } \\
\text { Science }\end{array}$ & Scielo & Total \\
\hline $\begin{array}{l}\text { "Youth and adult education" AND "teacher } \\
\text { training" AND "Paulo Freire" }\end{array}$ & 0 & 1 & 1 & 2 \\
\hline "Youth and adult education" AND "Paulo Freire" & 9 & 10 & 8 & 27 \\
\hline "Teacher training" AND "Paulo Freire" & 15 & 27 & 16 & 59 \\
\hline $\begin{array}{l}\text { "Adults and Young Adults Education" AND } \\
\text { "teacher training" AND "Paulo Freire" }\end{array}$ & 0 & 0 & 0 & 0 \\
\hline $\begin{array}{l}\text { "Adults and Young Adults Education" "Paulo } \\
\text { Freire" }\end{array}$ & 0 & 0 & 0 & 0 \\
\hline $\begin{array}{l}\text { "Adult education" AND "teacher training" AND } \\
\text { "Paulo Freire" }\end{array}$ & 0 & 1 & 1 & 2 \\
\hline "Adult education" AND "Paulo Freire" & 60 & 26 & 13 & 101 \\
\hline $\begin{array}{l}\text { "formation of teachers" AND "Youth and adult } \\
\text { education" AND "Paulo Freire" }\end{array}$ & 0 & 0 & 0 & 0 \\
\hline $\begin{array}{l}\text { "Youth and Young adult education" AND "Paulo } \\
\text { Freire" }\end{array}$ & 0 & 0 & 0 & 0 \\
\hline $\begin{array}{l}\text { "Adults and Young Adults Education" } \\
\text { "formation of teachers" AND "Paulo Freire" }\end{array}$ & 0 & 0 & 0 & 0 \\
\hline $\begin{array}{l}\text { "Adult education" AND "formation of teacher" } \\
\text { AND "Paulo Freire" }\end{array}$ & 0 & 0 & 0 & 0 \\
\hline $\begin{array}{l}\text { "Youth and adult education" AND "teacher } \\
\text { training programs" AND "Paulo Freire" }\end{array}$ & 0 & 0 & 0 & 0 \\
\hline "teacher training programs" AND "Paulo Freire" & 0 & 0 & 0 & 0 \\
\hline $\begin{array}{l}\text { "Adults and Young Adults Education" AND } \\
\text { "teacher training programs" AND "Paulo Freire" }\end{array}$ & 0 & 0 & 0 & 0 \\
\hline $\begin{array}{l}\text { "Adult education" AND "teacher training } \\
\text { programs" AND "Paulo Freire" }\end{array}$ & 0 & 0 & 0 & 0 \\
\hline $\begin{array}{l}\text { "Youth and Adult Education" AND "teacher } \\
\text { education programmes" AND "Paulo Freire" }\end{array}$ & 0 & 0 & 0 & 0 \\
\hline $\begin{array}{l}\text { "teacher education programmes" AND "Paulo } \\
\text { Freire" }\end{array}$ & 6 & 0 & 0 & 6 \\
\hline $\begin{array}{l}\text { "Adults and Young Adults Education" AND } \\
\text { "teacher education programmes" AND "Paulo } \\
\text { Freire" }\end{array}$ & 0 & 0 & 0 & 0 \\
\hline $\begin{array}{l}\text { "Adult education" AND "teacher education } \\
\text { programmes" AND "Paulo Freire" }\end{array}$ & 0 & 0 & 0 & 0 \\
\hline Total & & & & 182 \\
\hline
\end{tabular}

Fonte: Autoria própria (2021)

Alguns dos artigos foram indexados em mais de uma base de dados científicos, então, foi necessário retirar os duplicados. Os números dos artigos captados, de acordo com as palavras-chave, estão expostos na Tabela 2. 


\section{-Revista de Iniciação à Docência, v.6 , n. 2, 2021- Publicação: dezembro, 2021 - ISSN 2525-4332}

Tabela 2: Resumo da RBS com as palavras-chave para o estudo

\begin{tabular}{|l|l|}
\hline Número de artigos sem filtro & 182 \\
\hline Número de artigos após verificação de livros e congressos & 131 \\
\hline Número de artigos após verificação de duplicatas & 120 \\
\hline
\end{tabular}

Fonte: Autoria própria (2021)

O levantamento inicial resultou em 182 (cento e oitenta e dois) artigos e, após a eliminação das duplicatas, artigos publicados em livros e congressos, restaram 120 (cento e vinte). Realizada a leitura de títulos, palavras-chave e, quando necessário, do resumo, os artigos não pertinentes à pesquisa foram retirados, restando 105 (cento e cinco).

Realizou-se, então, nova leitura destes 105 (cento e cinco) artigos, analisando-se quais estavam relacionados com o objetivo desta pesquisa.

\section{Conforme Pagani, Kovaleski e Resende (2015, p. 10), o Methodi Ordinatio:}

(...) emprega uma equação para classificar os papéis, o Index Ordinatio (Inordinatio), visa selecionar e classificar os artigos de acordo com sua relevância científica, levando em consideração os principais fatores a serem considerados em um artigo científico: o fator de impacto da revista em que o artigo foi publicado, o número de citações e o ano de publicação. A tarefa de classificação é realizada antes da análise sistemática, para que a importância do papel seja reconhecida nas fases iniciais do processo.

O referido método é estruturado em nove etapas, visando selecionar artigos de acordo com sua relevância científica. As etapas do Methodi Ordinatio são as seguintes:

1. Estabelecendo a intenção de pesquisa: Deve estar relacionada à linha de pesquisa na qual o pesquisador está vinculado e/ou seu objeto de pesquisa. Para esta pesquisa, a intenção foi identificar o que foi produzido pela comunidade acadêmica, sobre o tema da formação de professores para a educação de jovens e adultos, bem como as contribuições de Paulo Freire.

2. Pesquisa preliminar com as palavras-chave nas bases de dados: Constituiu-se em uma pesquisa preliminar exploratória com as palavras-chave nas bases de dados. As palavras-chave para esta investigação em inglês foram "Youth and Adult Education, Teacher Training AND Paulo Freire”, escolhidas para delimitar o nicho da pesquisa. Nesta etapa é importante testar as palavras e seus boleadores. É necessário que o pesquisador trabalhe com um gerenciador de referências como Mendeley ou Zotero, por exemplo.

3. Definição da combinação das palavras-chave e bases de dados: As bases escolhidas para esta coleta de dados foram: Science Direct, Web of Science, Scopus e Scielo. As palavras para esta pesquisa ficaram: "Youth and Adult Education" e algumas variações da expressão Educação de Jovens e Adultos que podem acontecer na língua inglesa, como por exemplo: "Adults and Young adult education" e "adult education" foram usadas. Ocorreu também com a palavra formação de professores, onde foram utilizadas as seguintes palavras: "Teacher Training", "formation of teachers", "teacher training programs" e "teacher educations programmes" e a expressão "Paulo Freire".

4. Busca final nas bases de dados: Realização da pesquisa definitiva nas bases de dados e fazer a coleta utilizando o gerenciador. A busca final nas bases citadas na etapa 3 trouxe um total de 182 artigos. Foi utilizado o Mendeley como gerenciador de referências para a coleta e armazenamento dos dados. A pesquisa não abrangeu uma delimitação temporal. 


\section{-Revista de Iniciação à Docência, v.6 , n. 2, 2021- Publicação: dezembro, 2021 - ISSN 2525-4332}

5. Procedimentos de filtragem: É importante usar as palavras-chave e os filtros de cada base de forma mais padronizada possível. Ainda, é preciso aplicar procedimentos de filtragem como: a) exclusão de trabalhos duplicados; b) leitura dos títulos com a intenção de eliminar os que não estão relacionados ao tema; c) conferir se são apenas artigos, pois livros e capítulos são descartados por não existir um fator de impacto para os mesmos. Após esta etapa, dos 182 artigos encontrados, a pesquisa ficou com 105 artigos que tinham relações com os temas.

6. Identificação do fator de impacto, do ano e número de citações: As fontes utilizadas para esta etapa foram o Google Scholar, para averiguar o número de citações e o site da base Scopus para encontrar os fatores de impacto: CiteScore, SNIP e SJR. Os artigos foram organizados em uma planilha na seguinte ordem de colunas: artigo, ano, número de citações e fatores de impacto.

7. Classificando os artigos utilizando o InOrdinatio: Nesta etapa aplicou-se a equação InOrdinatio: $=(\mathrm{IF} / / 1,000)+\alpha *[10-($ ResearchYear-PublishYear $)]+(\Sigma \mathrm{Cl}))$. Onde IF é o fator de impacto, $\alpha$ é um fator de ponderação que varia de 1 a 10 a ser atribuído pelo pesquisador; ResearchYear é o ano em que a pesquisa foi desenvolvida; PublishYear é o ano em que o artigo foi publicado; e $\Sigma \mathrm{Ci}$ é o número de vezes que o artigo foi citado.

8. Localizando os artigos em formato integral: Buscar os artigos completos através dos bancos de dados e sites dos periódicos onde foram publicados.

9. Leitura sistemática e análise dos artigos: A leitura completa foi realizada com 10 artigos onde os índices InOrdinatio foram os mais altos. (PAGANI; KOVALESKI; RESENDE, 2015, p. 10-12).

Após a aplicação da fórmula para o cálculo do In Ordinatio, foi realizada a leitura e divisão dos artigos em categorias. As categorias definidas e sua composição foram: 46 (quarenta e seis) artigos que abordaram somente o tema EJA; com a temática da formação de professores, com 49 (quarenta e nove) artigos; e 10 (dez) artigos sobre a formação de professores e EJA. Os artigos analisados foram os da categoria formação de professores e EJA.

A partir desses dados, prosseguiu-se a pesquisa com a leitura completa dos artigos, com o objetivo de descrever, brevemente, a ideia central de cada um, identificar seus objetivos, e mostrar como as questões referentes à formação de professores, EJA e as contribuições de Paulo Freire foram tratadas, em conjunto. Esse processo conferiu densidade à análise, no estabelecimento das relações, interfaces, limites e aberturas que o conjunto do material tratado pode oferecer à pesquisa.

\section{Classificação e resultados}

Os artigos utilizados, para a análise, foram os da categoria formação de professores e EJA, no total de 10 (dez); sendo que 3 (três) foram publicados no ano de 2021, 2 (dois) no ano de 2019, e os outros 5 (cinco) artigos foram publicados nos anos de 2020, 2018, 2014, 2012 e 2009; conforme disposto na Tabela 3. 
-Revista de Iniciação à Docência, v.6 , n. 2, 2021-

Publicação: dezembro, 2021 - ISSN 2525-4332

Tabela 3: Artigos selecionados pelo In Ordinatio

\begin{tabular}{|c|l|c|c|}
\hline \multicolumn{2}{|l|}{ Artigo } & Ano & $\begin{array}{l}\text { In } \\
\text { Ordinatio }\end{array}$ \\
\hline $2^{\circ}$ & Continuing teacher training for schools in liberty deprivation units. & 2021 & 50 \\
\hline $6^{\circ}$ & $\begin{array}{l}\text { A unidade na diversidade em Paulo Freire: Avanços para a } \\
\text { transformação educacional. }\end{array}$ & 2021 & 50 \\
\hline $7^{\circ}$ & $\begin{array}{l}\text { A atualidade de Paulo Freire em tempos de pandemia: Tecendo } \\
\text { diálogos sobre os desafios da educação e do fazer docente. }\end{array}$ & 2021 & 50 \\
\hline $18^{\circ}$ & $\begin{array}{l}\text { Educação Popular e cidadania: perspectivas da educação popular e } \\
\text { docência face aos desafios da alfabetização na educação de jovens } \\
\text { e adultos - EJA }\end{array}$ & 2020 \\
\hline $25^{\circ}$ & $\begin{array}{l}\text { Diversidade e Multiculturalismo: formação docente necessária à } \\
\text { Educação de Jovens e Adultos }\end{array}$ & 2019 \\
\hline $\begin{array}{c}28 \\
\circ\end{array}$ & $\begin{array}{l}\text { La pedagogia del oprimido, la investigación en sala de clases y los } \\
\text { profesores como investigadores }\end{array}$ & 2019 \\
\hline $37^{\circ}$ & $\begin{array}{l}\text { Revisitando Knowles e Freire: Andragogia versus pedagogia, ou O } \\
\text { diálogo como essência da mediação sociopedagógica }\end{array}$ & 2018 \\
\hline $\begin{array}{c}56 \\
\circ\end{array}$ & $\begin{array}{l}\text { O processo grupal e a educação de jovens e adultos } \\
60\end{array}$ & $\begin{array}{l}\text { A constituição da docência na educação de jovens e adultos } \\
\circ\end{array}$ & 2009 \\
\hline $\begin{array}{c}66 \\
\circ\end{array}$ & $\begin{array}{l}\text { Estilos de pensamentos de professores de química da educação de } \\
\text { jovens e adultos (EJA) do Paraná em processo de formação docente }\end{array}$ & 2014 & 26 \\
\hline
\end{tabular}

Fonte: Autoria própria (2021)

A categoria retratada nesta pesquisa se refere à educação de jovens e adultos e a formação de professores desse segmento de ensino, na qual, o primeiro artigo é, também, o segundo na classificação do In Ordinario, intitulado Continuing teacher training for schools in liberty deprivation units. Com o objetivo de investigar as necessidades formativas de professores da EJA, que atuam em salas de aula de unidades de privação de liberdade, fundamentada na pedagogia libertadora de Paulo Freire, o artigo analisa os dizeres dos docentes sobre a busca de formação continuada, indicação de melhoria da prática educativa, novos conhecimentos e a permanência ou ascensão no mercado de trabalho.

A formação continuada dos professores advém dos processos educativos do movimento de aprender uns com os outros e propor novas estratégias. O diálogo, na perspectiva de Freire (2011), permite que as interações humanas aconteçam no interior de práticas sociais e se desenvolvam numa perspectiva de humanização, coletividade e constante busca por ser mais (MORAES; ONOFRE, 2021).

O sexto artigo retrata a atualidade da teoria freireana, por meio da definição de unidade na diversidade e desenvolvimento do conceito chave do autor, em diferentes obras. Destaca que a educação escolar precisa se pautar pela "unidade na diversidade", entender em uma perspectiva intercultural as relações dos sujeitos, a partir do diálogo, 


\section{-Revista de Iniciação à Docência, v.6 , n. 2, 2021- \\ Publicação: dezembro, 2021 - ISSN 2525-4332}

estar em união quanto à educação e seus integrantes, como, também, defender que a igualdade de resultados e de diferenças são importantes e indissociáveis.

A partir dos pressupostos freireanos, a Universidade de Barcelona, na Espanha, desenvolveu uma sequência de atividades para escolas, denominadas como Atuações Educativas de Êxito, AEE:

As AEE perpassam todo o processo de desenvolvimento de uma comunidade de aprendizagem por meio dos princípios da aprendizagem dialógica: diálogo igualitário, dimensão instrumental, inteligência cultural, transformação, criação de sentido, solidariedade e igualdade nas diferenças. (BRAGA, MELLO e BACHEGA, 2021, p. 10)

A mesma atividade foi aplicada no Brasil, com alunos da EJA, e o resultado obtido foi a participação dos estudantes e da comunidade nos processos educativos e decisórios, com diálogo e presença de todos os agentes educativos no processo. Observa-se que a aplicação e desenvolvimento do método de Freire acontece em vários países, demonstrando o quão grande é a sua dimensão.

$\mathrm{O}$ artigo 7, intitulado A atualidade de Paulo Freire em tempos de pandemia: Tecendo diálogos sobre os desafios da educação e do fazer docente, foi dividido em três momentos. O primeiro estabeleceu um diálogo com Freire, a partir do resgate de suas memórias e de elementos de seu contexto histórico, que o constituíram como docente e intelectual da práxis. Tal articulação, por meio de uma pedagogia problematizadora e dialógica, fez funcionar, em tempos de pandemia, os movimentos reacionários de educação em curso, entender a atuação dos docentes (com referência a algumas lives) e despertar o contexto no qual se está inserido.

No segundo ponto, apresentou a contextualização histórica e contemporânea elucidando os tempos de pandemia, destacando como atuar com os alunos da EJA em distanciamento social, embasado nos pressupostos freireanos, e como a educação cumpre o papel de contribuir e ampliar a compreensão sobre a realidade. Na terceira seção, apresentou a conjugação do verbo esperançar, ao elaborar um exercício de pensamento amparado nos principais conceitos de Paulo Freire. Logo, apresentou a reflexão sobre a formação de professores que atuam na EJA, por meio de lives.

O artigo cujo título é Educação popular e cidadania: perspectivas da educação popular e docência face aos desafios da alfabetização na educação de jovens e adultos - EJA, aborda o processo de alfabetização na EJA e a formação dos professores: “deverá estar capacitado para conseguir ensinar de forma significativa, sabendo realizar a mediação entre o conhecimento que os alfabetizandos trazem das práticas cotidianas com o conteúdo estabelecido pelo currículo escolar" (BORGES, 2020, p. 4).

Ainda, nessa perspectiva, apresenta um curso de formação continuada para os professores alfabetizadores, utilizando as contribuições da Psicopedagogia em diálogo com a concepção freireana. No decorrer da leitura do artigo, tem-se o esclarecimento de 


\section{-Revista de Iniciação à Docência, v.6 , n. 2, 2021- \\ Publicação: dezembro, 2021 - ISSN 2525-4332}

que a formação inicial para a EJA é praticamente inexistente e que o professor que atua nesse segmento necessita buscar conhecimentos em cursos de formação continuada.

O $25^{\circ}$ artigo, intitulado Diversidade e Multiculturalismo: formação docente necessária à Educação de Jovens e Adultos, apresentou como objetivo possibilitar uma reflexão a respeito da formação docente impreterível para a atuação nos designados "coletivos diversos", que se compõem na modalidade de EJA. Nesse artigo, as autoras destacam os chamados coletivos diversos, encontrados nas turmas da EJA. Assim, relatam que os termos "Educação para diversidade, multiculturalismo e solidariedade se fazem tão presentes nessa modalidade educativa, refletindo outros aspectos característicos de seus educandos" (HARACEMIV; SOEK; MILEK, 2019, p. 163).

$\mathrm{O}$ artigo analisa algumas obras de Paulo Freire e conclui que:

Paulo Freire, precursor e um dos maiores influenciadores para a Educação de Jovens e Adultos no País desenvolveu um pensamento pedagogicamente político, seu maior objetivo na educação foi o de conscientizar os sujeitos, leválos a compreender sua situação e também a refletir sobre a própria libertação e autonomia. Ressalta a questão da inconclusão/inacabamento humano. (HARACEMIV; SOEK; MILEK, 2019, p. 163)

O artigo também destaca a importância de os professores que atuam na EJA conhecerem a realidade dos alunos, as peculiaridades educacionais, suas marcas identitárias e local cultural, para que possam estabelecer relações mais próximas e novos sentidos na educação dos alunos dessa modalidade.

O artigo La pedagogia del oprimido, la investigación em sala de clases y los profesores como investigadores (WILLIAMSON; HIDALGO, 2019) relata um processo investigativo realizado em escolas, colégios e centros de educação de jovens e adultos no Chile, analisa opiniões em entrevistas, palestras e reuniões de professores que aplicam a metodologia freireana. Para Williamson e Hidalgo (2019), a partir dessa metodologia, o professor passa a ser um ator coprotagonista da investigação, que descobre, juntamente aos alunos, um processo ativo na construção do conhecimento, porém:

\footnotetext{
Não basta impulsionar formas diferentes de fazer educação crítica se não houver capacidade de instalá-las no currículo oficial (dimensão política) e de gerenciá-las de forma democrática (gestão participativa), para a qual não basta qualquer teoria educacional. A abordagem de Freire deve ser assumida como uma teoria que, sem ser totalizante como uma A ideologia ou teoria científica que tende à generalização, tem uma dimensão explicativa da realidade e outra dimensão prático-transformadora. (WILLIAMSON; HIDALGO, 2019, p. 23)
}

Os autores concluíram que os professores, ao atuarem como coprotagonistas no processo de libertação em sala de aula, conseguiram desenvolver, nos alunos, conhecimento e discernimento diante dos fenômenos da realidade.

Barros (2018), no artigo intitulado Revisitando Knowles e Freire: Andragogia versus pedagogia, ou O dialógico como essência da mediação sociopedagógica, analisa as principais contribuições do modelo andragógico, de Knowles, e o conceito de dialogicidade, de Freire, para o educador contemporâneo, na atuação da mediação sociopedagógico. 


\section{-Revista de Iniciação à Docência, v.6 , n. 2, 2021- \\ Publicação: dezembro, 2021 - ISSN 2525-4332}

Na análise realizada, Barros (2018) aponta a importância da andragogia, da abertura do debate sobre como ensinar os adultos a aprenderem, pois existia pouca teoria sobre isso, mas destaca a pedagogia freireana, que:

(...) abriu caminho na criação de fundamentos político-filosóficos para a práxis educacional de cariz transformador. Isso não significa forçosamente abandonar a andragogia, que efetivamente se sofisticou em alguns contextos, vindo a representar o paradigma mais adotado e mostrando que, a partir da sua base teórico-pedagógica, há elementos suficientes para superar a tendência de querer construir uma especificidade para a EA numa perspetiva de disjunção, baseada em estratégias e procedimentos de mera diferenciação didática (BARROS, 2018, p. 14).

A pedagogia freireana aborda a mediação sociopedagógica como um ato dialógico, político e gnosiológico, além de perceber as características de um educador, que, na visão do pensamento de Freire, é democrático e solidário com a causa dos oprimidos.

$\mathrm{O}$ artigo disposto na posição $56^{\circ}$, pelo In ordinatio, denominado O processo grupal e a educação de jovens e adultos, de Afonso, Silva e Abade (2009), discute o processo grupal na educação de jovens e adultos, apontando diretrizes metodológicas que contribuam para o trabalho de coordenadores de grupo e educadores. A pesquisa é embasada no livro Pedagogia da autonomia, de Paulo Freire, sobre o qual os autores abordam a dialogicidade e a abertura para o mundo pelo olhar do educando e, também, sobre a comunicação e a aprendizagem no grupo operativo, de Enrique Pichon Rivière.

$\mathrm{Na}$ pedagogia de Freire e na teoria do grupo operativo existe a ênfase na reciprocidade e complementaridade do aprender e do ensinar. O processo de facilitar vínculos e sentimentos de pertencimento, os quais aproximam o educador do educando e vice-versa, também é destacado. Afonso, Silva e Abade (2009, p. 8) finalizam seu artigo com a seguinte declaração:

É no contato humano, na autonomia, na reflexividade e na dialogicidade que educadores e alunos resgatam a relação necessária para o enfrentamento das suas dificuldades e para o seu crescimento como sujeitos e cidadãos diante do conhecimento. O grupo é o campo privilegiado para tal interação (SILVA; ABADE, 2009, p. 8).

Para Laffin (2012), autora do artigo A constituição da docência na educação de jovens e adultos, aborda reflexões acerca da formação docente para a EJA. Nestas, remete às práticas que professores utilizam em sala de aula, com os alunos, e à percepção que os professores necessitam ter sobre os alunos, pois estes, em algum momento, passarão por situações de exclusão no ambiente escolar.

Na pesquisa, destaca que os docentes "captam nas falas de seus alunos de mais idade uma valorização da escolarização como um elemento importante para o seu desenvolvimento, como formas de maior participação social e maiores possibilidades de inclusão e manutenção no trabalho" (LAFFIN, 2012, p. 14). Assim, a formação docente para o público que atua na EJA assume um compromisso ético-político e atua para que 


\section{-Revista de Iniciação à Docência, v.6 , n. 2, 2021- \\ Publicação: dezembro, 2021 - ISSN 2525-4332}

esses alunos acessem o conhecimento e consigam levá-lo para a sua vida pessoal e profissional.

No artigo Estilos de pensamentos de professores de química da educação de jovens e adultos (EJA) do Paraná em processo de formação docente, de Lambach e Marques (2014), a pesquisa foi desenvolvida com professores de química da EJA e baseada nos pressupostos teóricos metodológicos de Paulo Freire e Ludwik Fleck. O autor realizou um curso de extensão, no qual os professores participantes tiveram momentos presenciais e desenvolveram atividades com seus alunos, em classe, os quais também foram validados como horas do curso. O contexto do curso foi de conhecimento acerca da concepção dialógica problematizadora, defendida por Freire, e sua aplicação, em sala, com alunos da EJA.

A análise realizada destacou que a formação continuada para professores precisa ter significado e que os conteúdos ministrados nos cursos precisam ser aplicáveis em sala de aula. Destacou que "quando o professor assume uma nova postura pedagógica, no presente caso, crítico-problematizadora, é preciso que ele se desvincule da postura bancária" (LAMBACH; MARQUES, 2014, p. 14). Assim, após as situações apresentadas, os conceitos recebidos e as reflexões realizadas, após aplicação em sala, com os alunos, levaram a uma reflexão crítica sobre a prática.

$\mathrm{Na}$ análise dos artigos selecionados pelas palavras-chave e, posteriormente, na aplicação da equação do In ordinatio, observa-se que, dos 10 (dez) artigos relacionados a Paulo Freire, formação de professores e EJA, 4 (quatro) são dos anos de 2020 e 2021. Assim, a hipótese levantada é a de que, nestes anos, devido às comemorações do centenário de nascimento de Freire, houve um aumento de publicações referentes ao autor. Considerando que 3 (três) artigos, do 10 (dez) analisados, são dos anos de 2018 e 2019, tem-se que 70\% dos artigos são dos últimos 4 (quatro) anos, o que demonstra o quanto ainda é atual a pedagogia desenvolvida por Paulo Freire.

Outro ponto analisado é que nos 37 (trinta e sete) primeiros artigos (Figura 1), o ano de publicação varia entre 2014 e 2021, lembrando-se, contudo, que não foi estabelecida delimitação temporal durante a pesquisa, e que, portanto, o in ordinatio apresentou publicações mais recentes para este estudo. 


\section{-Revista de Iniciação à Docência, v.6 , n. 2, 2021- \\ Publicação: dezembro, 2021 - ISSN 2525-4332}

Figura 1: Tabela In ordinatio

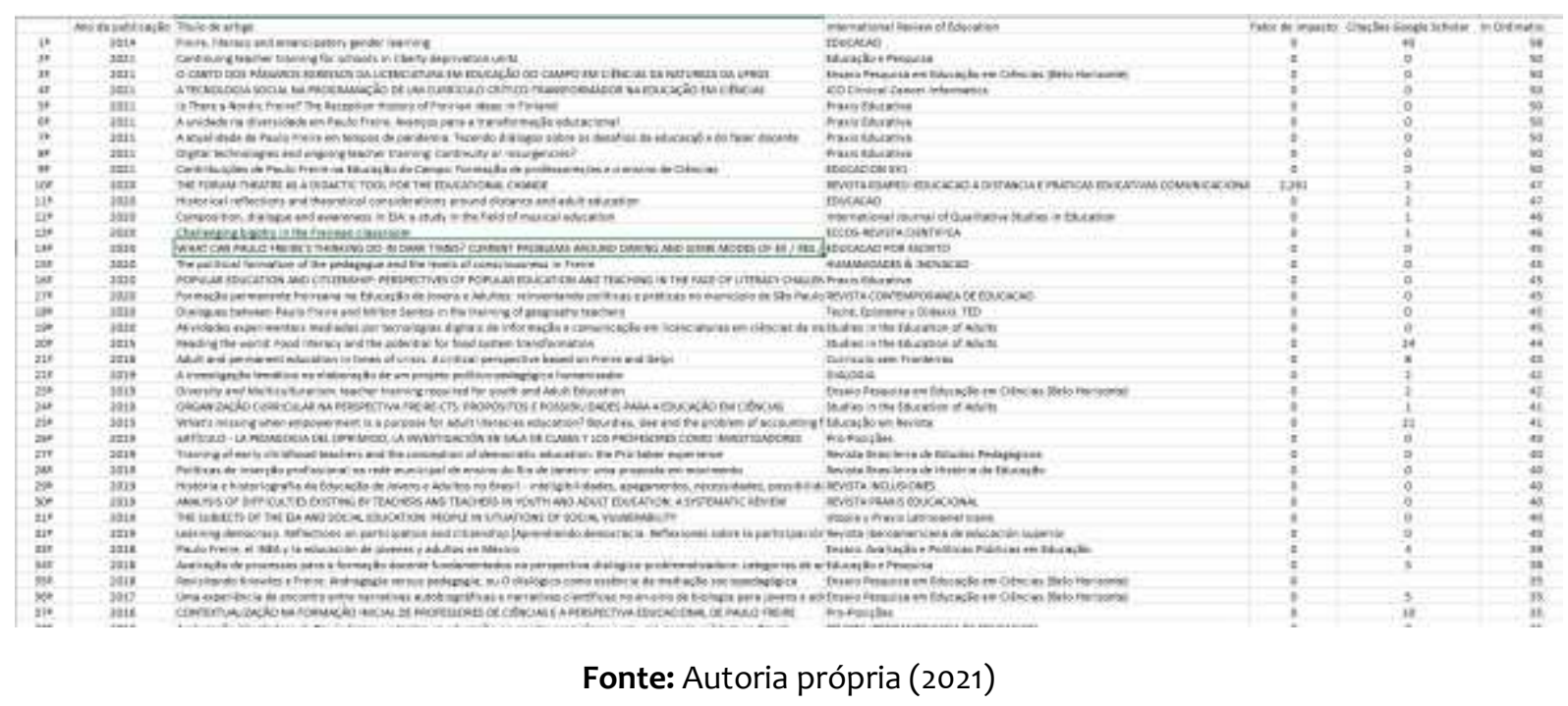

Ao analisar a Figura 1, observou-se que o tema abordado, "Paulo Freire", é atual e relevante para a educação no Brasil e em outros países, pois as discussões acerca do método freireano ainda são fontes de publicações de inúmeras pesquisas e discussões. Acredita-se que essas discussões colaboram para o aprimoramento do processo de ensino e aprendizagem, para que a educação, como um todo, esteja sempre em desenvolvimento, acompanhando as mudanças que ocorrem na sociedade.

\section{Considerações Finais}

A ideia inicial da utilização do Methodi Ordinatio para a busca de artigos, nas bases de dados, era responder à pergunta: Qual a contribuição de Paulo Freire para a formação de professores que atuam na Educação de Jovens e Adultos? Porém, as combinações de palavras trouxeram artigos relacionados não somente à EJA, mas, principalmente, à formação de professores e às contribuições do autor, o que reflete, na equação matemática utilizada, na obtenção de artigos com maiores índices. Logo, vê-se que fizeram referência à contribuição de Paulo Freire para a formação de professores, nas mais diferentes áreas publicadas, no ano de 2021.

Pode-se observar a abrangência do tema, pois a metodologia seleciona os melhores artigos publicados nas bases de dados, orientados pelo fator de impacto, número de citações, ano de publicação e ano da pesquisa. Porém, foi realizada a leitura somente dos artigos que contribuíram para responder a pergunta de partida do artigo, e, com isso, o resultado final apontou dez artigos sobre Paulo Freire, formação de professores e EJA, tratados conjuntamente.

Ao analisar os artigos, observou-se a grande contribuição de Paulo Freire para a EJA, inclusive fora do Brasil, pois artigos publicados na Espanha e no Chile fizeram parte do portfólio desta pesquisa. Além disso, os artigos analisados abordam desde discussões 
referentes à atuação com discentes em privação de liberdade, estudo realizado na Espanha e replicado no Brasil, com alunos da EJA, em que professores, coordenadores e alunos foram entrevistados, até o contexto atual vivenciado pelos docentes, com o ensino remoto e a aprendizagem de alunos da EJA através de lives.

Assim, percebe-se que a contribuição de Paulo Freire foi e é muito presente na educação, em especial na EJA. A formação de professores para esse segmento da educação acontece, na maioria das vezes, na formação continuada, na qual existe a orientação para que sejam abordados conteúdos voltados para a realidade dos alunos, além de levantar a possibilidade da formação crítica-problematizadora, visando a formação de sujeitos autônomos e críticos para a sociedade.

Observa-se, porém, uma lacuna na pesquisa, pois, ao realizar a leitura dos títulos e resumos, e ao classificar os artigos na temática a que cada um pertencia (formação de professores, formação de professores e EJA e somente EJA), foram analisados os que abordavam o tema central desta pesquisa, perfazendo somente 10 (dez) artigos. Na classificação final, foram relacionados 49 (quarenta e nove) artigos com a abordagem sobre formação de professores e Paulo Freire, e 45 (quarenta e cinco) artigos que abordaram somente o tema EJA.

Dessa forma, a lacuna observada mostra que ainda há poucos artigos relacionados à formação de professores, Paulo Freire e a EJA, estudados conjuntamente, tema que pode ser amplamente explorado com outros pontos de abordagem.

\section{Agradecimento}

O presente trabalho foi realizado com o apoio da Coordenação de Aperfeiçoamento de Pessoal de Nível Superior, CAPES, Brasil, Código de Financiamento 001.

\section{Referências}

AFONSO, Maria Lúcia Miranda; SILVA, Marcos Vieira; ABADE, Flávia Lemos. O processo grupal e a educação de jovens e adultos. Psicologia em Estudo, Maringá, v. 14, n. 4, p. 707715, out./dez. 2009.

ARAÚJO, Mairce da Silva et. al. A atualidade de Paulo Freire em tempos de pandemia: Tecendo diálogos sobre os desafios da educação e do fazer docente. Práxis Educativa, Ponta Grossa, v. 16, e2116609, 2021.

BARROS, Roanna. Revisitando Knowles e Freire: Andragogia versus pedagogia, ou O dialógico como essência da mediação sociopedagógica. Revista Educação e Pesquisa, São Paulo, v. 44, e173244, 2018.

BORGES, Galbênia Ferreira. Educação Popular e cidadania: perspectivas da educação popular e docência face aos desafios da alfabetização na educação de jovens e adultos EJA . Revista Humanidade e Inovação, Palmas, v. 7, n. 19, 2020. 
-Revista de Iniciação à Docência, v.6 , n. 2, 2021-

Publicação: dezembro, 2021 - ISSN 2525-4332

BRAGA, Fabiana Marini; MELLO, Roseli Rodrigues; BACHEGA, Denise. A unidade na diversidade em Paulo Freire: avanços para a transformação educacional. Práxis Educativa, Ponta Grossa, v. 16, e2116609, 2021.

BRASIL. Constituição da República Federativa do Brasil, Brasília, DF: Senado Federal, 1988.

BRASIL. [Lei Darcy Ribeiro]. LDB: Lei de Diretrizes e Bases da Educação Nacional: lei n 9.394, de 20 de dezembro de 1996, que estabelece as diretrizes e bases da educação nacional. 5. Ed. - Brasília: Câmara dos Deputados, Coordenação Edições Câmara, 1996.

CASSOL, Atenuza Pires; PEREIRA, Jodielson da Silva; AMORIM, Antonio. Educação de Jovens e Adultos: contribuições freireanas para a formação cidadã. Criar educação.

Criciúma, V. 10, nº 1, jan/jul 2021.

FREIRE, Paulo. Extensión o comunicación? La concientización en el mundo rural. Buenos Aires, Argentina: Siglo XXI, 1975.

FREIRE, Paulo. Pedagogia da Autonomia: Saberes necessários à prática educativa. $65^{\mathrm{a}}$ ed. Rio de Janeiro/São Paulo: Paz e Terra, 2020a.

FREIRE, Paulo. Pedagogia do oprimido. $74^{\mathrm{a}}$ ed. Rio de Janeiro/São Paulo: Paz e Terra, 2020b.

GALVÃO, Maria Cristina Barbosa; RICARTE, Ivan Luiz Marques. Revisão sistemática de literatura: conceituação, produção e publicação. Logeion: Filosofia da informação, v. 6, n. 1, p. 57-73, 2019.

HARACEMIV, Sonia Maria Chaves; SOEK, Ana Maria; MILEK, Emanuelle. Diversidade e Multiculturalismo: formação docente necessária à Educação de Jovens e Adultos.

Dialogia. São Paulo, n. 31, p. 155-164, jan./abr. 2019.

LAFFIN, Maria Hermínia Lage Fernandes. A constituição da docência na educação de jovens e adultos. Currículo sem Fronteiras, v.12, n.1, pp. 210-228, Jan/Abr 2012.

LAMBACH, Marcelo; MARQUES, Carlos Alberto. Estilos de pensamentos de professores de química da educação de jovens e adultos (EJA) do Paraná em processo de formação docente. Revista Ensaio, Belo Horizonte, v.16, n. 01, p. 85-100, jan-abr, 2014

MORAES, Luciana Ferreira da Silva; ONOFRE, Elenice Maria Cammarosano. Treinamento contínuo de professores para escolas em unidades de privação de liberdade. Revista do Centro de Educação UFSM, Santa Maria, v. 46, 2021.

PAGANI, Regina Neli; KOVALESKI, João Luiz; RESENDE, Luis Maurício. Methodi Ordinatio: a proposed methodology to select and rank relevant scientific papers encompassing the impact factor, number of citation, and year of publication. Scientometrics, v. 105, n. 3, p. 2109-2135, 2015.

PAULA, Adalberto Penha; BARBOSA, Roberto Gonçalves. Contribuições de Paulo Freire na Educação do Campo: Formação de professores/as e o ensino de Ciências. Práxis

Educativa, Ponta Grossa, v. 16, e2116609, 2021.

PELANDRÉ, Nilcea Lemos. Efeitos de longo prazo do método de alfabetização Paulo

Freire. Tese de doutorado. Universidade Federal de Santa Catarina, Florianópolis, 1998. 
PINTO, Álvaro Vieira. Sete lições sobre educação de adultos. $7^{\text {a }}$ ed. São Paulo: Cortez, 1991.

SUORANTA, Juha; TOMPERI, Tuukka. Existe um Freire nórdico? A História da Recepção das Ideias Freirianas na Finlândia, Trepo, v. 5, 2021. Disponível em:

http://www.jceps.com/archives/10480. Acesso em: 15 set. 2021.

WILLIAMSON, Guillermo; HIDALGO, Carolina. La Pedagogia del oprimido, la investigación em sala de clases y los profesores como investigadores. Educação em Revista. Belo Horizonte, Dossiê - Paulo Freire: O Legado Globa, v.35, e222219, 2019.

Recebido: 15.07.2021

Aprovado: 18.10.2021 